\title{
Estimation of Antioxidants Activity Through DPPH Inhibition Levels In Patients with Chronic HPV 16 Cervicitis
}

\author{
Ali M. A. Al-Kufaishi ${ }^{1}$, Lamia A. M. Al-Mashhedy ${ }^{2}$, Bushra Jaber Al-Rubaie ${ }^{3}$ \\ ${ }^{1}$ Iraq/Al-Furat Al-Awsat Technical University College of Health and Medical Techniques, Department of Medical \\ Laboratory Techniques, Kufa, Iraq 31003", ' ${ }^{2}$ University of Babylon, College of Science, Chemistry department/ \\ Iraq", ${ }^{3}$ University of Babylon, College of Medicine, Gynecology Department/Iraq
}

\begin{abstract}
In the present study, the DPPH scavenging activity from the primary methods to estimation the antioxidants activity in the body by an inverse relation between them. So, the levels of DPPH scavenging activity is reduced in the patient with HPV16 genotype chronic cervicitis $(\mathrm{G} 3=43.01 \pm 2.74$ in the serum, $\mathrm{G} 3=9.73 \pm 1.53$ in the mucus) and without ( $\mathrm{G} 2=47.22 \pm 4.50$ in the serum, $\mathrm{G} 2=15.51 \pm 1.41$ in the mucus)compared with healthy women $(\mathrm{G} 1=64.79 \pm 4.87$ in the serum, $\mathrm{G} 1=21.24 \pm 3.62$ in the mucus), this is a return to lowering antioxidants in the patients compared with healthy women. The deterioration in the antioxidants levels can cause cancer in the future or delay the response of the medication to inflammation.
\end{abstract}

Keywords: DPPH, Antioxidants activity, Chronic cervicitis, HPV, cervical cancer.

\section{Introduction}

Chronic cervicitis from the widespread diseases in gynecology, caused by delayed treatment or diagnosis $(1,2)$. From the clinical symptoms for this disease include abnormal vaginal discharge, lower genital pain and constant lochia. chronic cervicitis occurs due to infected cervical by a pathogen ${ }^{(3,4)}$. Human papillomavirus (HPV) is a common pathogen that causes chronic cervicitis. The high-risk HPV (HRHPV) is more than 180 genotypes that cause squamous epithelial hyperplasia because of the DNA of HR-HPV have the ability to synthesis oncoproteins that cause inhibition to tumor suppressor proteins such as "p53 and retinoblastoma protein (pRb)". So, the infected by HRHPV can lead to "cervical intraepithelial neoplasia" or cervical precancerous lesions ${ }^{(5,6)}$.

The chronic infection accompanied by increased free radicals and pro-oxidants, that have harmful effect to biological systems such as lipids, proteins and DNA, that cause ageing, cardiovascular disturbances, diabetes, and cancer ${ }^{(7)}$. While the antioxidants are the compounds, act as free radicals scavenging either by prevention or conversion mechanisms ${ }^{(8)}$. These antioxidants produced internally in living organs or intake by foods ${ }^{(9)}$. $\alpha, \alpha$-diphenyl- $\beta$-picrylhydrazyl (DPPH) is described as a stable free radical due to delocalisation electron overall whole molecule (Figure 1). therefore keep this molecule from dimerization. The DPPH from the mainly methods to evaluation of antioxidants activity for the biological systems ${ }^{(10)}$.

\section{Material and Method}

\section{Study design:}

The study design is a comparative study for healthy, chronic cervicitis patients with positive HPV 16 genotyping, and patients without HPV.

\section{Sample collection:}

HPV 16/18 genotyping detection by real-time PCR by taken specimens as tissues by cervical scraping and as Pap smear with mucus by the physician in the hospital Imam Sadiq and maternity hospital and children in Babil province, where keeping in $(2 \mathrm{ml})$ from phosphate buffer solution (PBS), in addition to serum for the same persons. The specimens collected depend on the criteria of chronic cervicitis such as age, number of pregnancy or abortion, infection delay, smoking, vaginal bleeding, lower abdominal pain and vaginal $\mathrm{pH}$. 


\section{Sample size calculation:}

The sample size calculated by applying the following equation ${ }^{(11)}$ :

$$
\mathbf{n}=\mathbf{Z}^{2} \mathbf{P}(\mathbf{1}-\mathbf{P}) / \mathbf{d}^{2}
$$

Where $\mathrm{Z}$ refer to $\mathrm{Z}$-score (equal 1.65), $\mathrm{d}$ is the absolute marginal error equal $10 \%, \mathrm{P}$ is the population (number of women that have cervicitis and undergo to cervical screen equal $8 \%$ ), therefore the number of samples equal to twenty for each group, but have been taken more than 20 for the chronic cervicitis without HPV 16/18 and healthy control (Table 1). The samples were collected for a period of six months.

Table 1: Groups classification.

\begin{tabular}{|l|l|l|}
\hline Groups & Description & No. of the patients \\
\hline G1 & Women with chronic HPV16/18 cervicitis & 20 \\
\hline G2 & Women with chronic cervicitis & 40 \\
\hline G3 & Healthy women & 40 \\
\hline
\end{tabular}

\section{Viral DNA extraction:}

Depended on viral gene-spin DNA extraction kit, can be extracted DNA and prepared to real-time PCR.

\section{Real-time PCR procedure:}

Have been used Bosphore HPV genotyping kit for real-time PCR to detect HPV 16/18 genotypes ${ }^{(12,13)}$.

\section{DPPH procedure:}

\section{Principle:}

DPPH has violet colour due to this delocalisation when dissolved in ethanol and absorbed at $517 \mathrm{~nm}$. This radical can accept a hydrogen atom from antioxidants to reduce the colour intensity from violet to yellow colour depending on the antioxidants power (Figure 1).

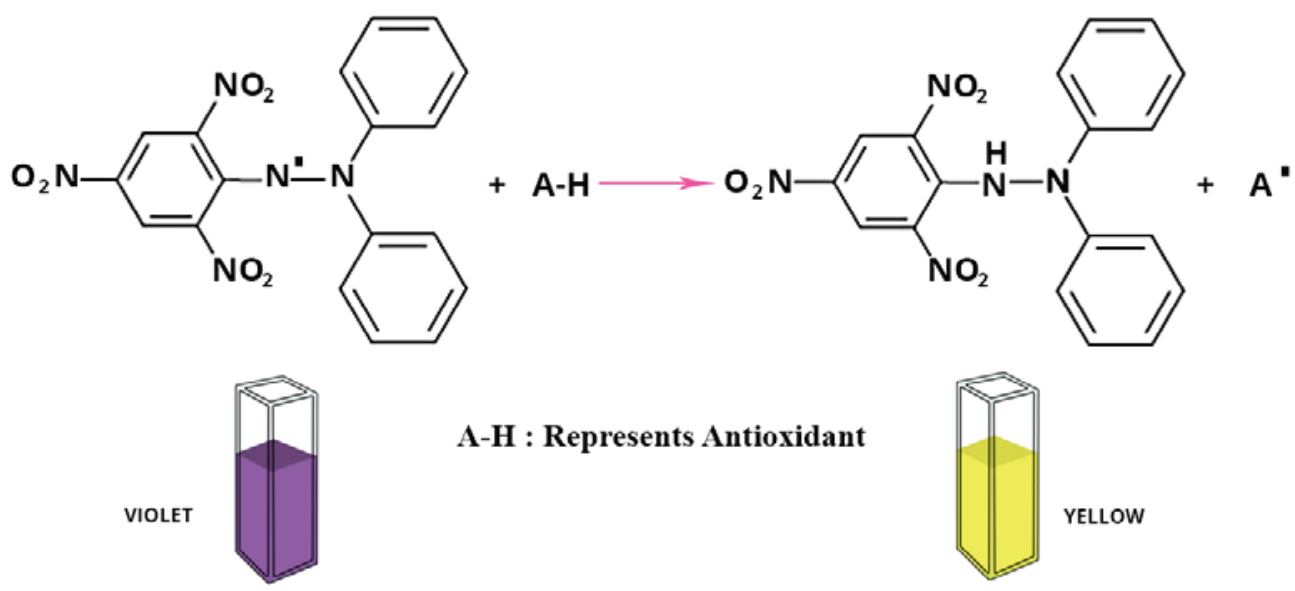

Fig. 1: DPPH reaction with A-H. 


\section{Procedure:}

With minor modify prepared the reagent $1(\mathrm{R} 1), \mathrm{DPPH}(0.1 \mathrm{mM})$ in absolute ethanol, and control from ascorbic acid $(20 \mathrm{mg} / \mathrm{dl})$, then the following steps ${ }^{(14)}$ :

\begin{tabular}{|c|c|c|c|}
\hline Reagent & 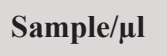 & control/ $/ \mu \mathrm{l}$ & Blank $/ \mu \mathrm{l}$ \\
\hline R1 & 1000 & 1000 & 1000 \\
\hline Serum & 100 & ------- & ------- \\
\hline Control & ------- & 100 & ------- \\
\hline D.W. & ------- & ------- & 100 \\
\hline
\end{tabular}

wait for $20 \mathrm{~min}$ at $25^{\circ} \mathrm{C}$. within dark condition, read absorbance at $517 \mathrm{~nm}$. The results can be calculated by the f ollowing relation:

\section{Statistical Analysis}

The data were entered into SPSS program version 23 to get on the variables as mean, standard deviation (SD), standard error (S.E), confidence interval and "one-way ANOVA. A $p$ value of $\leq 0.05$ was considered to be significant".

\section{Results and Discussion}

The results for the sixty women that undergo to cervical screen represented only twenty from the patients that suffer from the symptoms that related with chronic cervicitis have HPV positive of 16 genotype only according to real-time PCR results as showing from the amplification plot (Figure 2). Where another forty also have chronic cervicitis but due to other causes than HPV 16/18 genotyping.

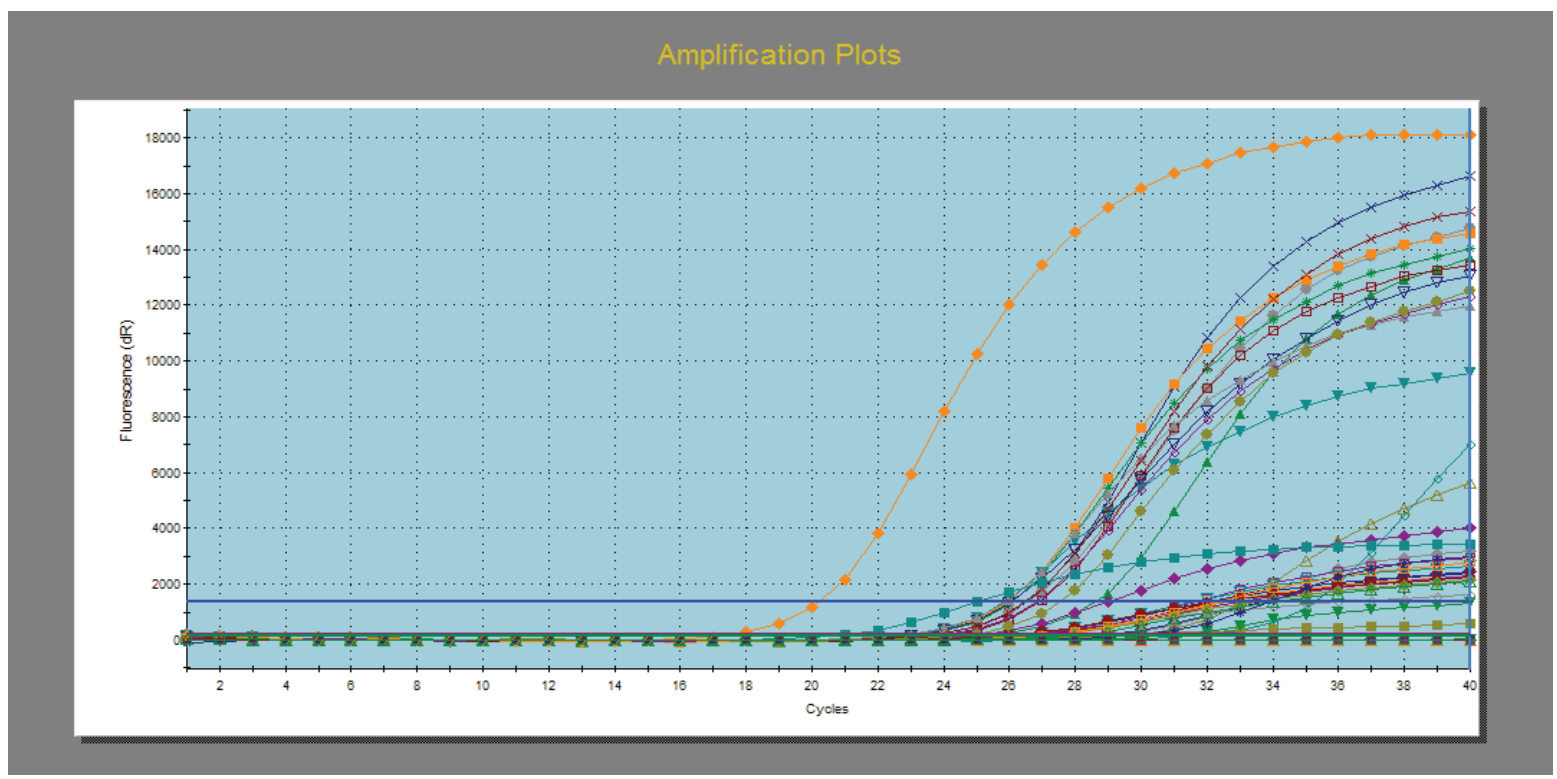

Fig. 2: Amplification plots of real-time PCR.

The DPPH results represented in (Table 2), were the results in G3 show the significant decrease in DPPH scavenging compared with G1, and G2 compared with G1, also in G3 compared with G2. 
Table 2: DPPH scavenging activity.

\begin{tabular}{|c|c|c|c|c|c|c|}
\hline \multirow{2}{*}{\multicolumn{2}{|c|}{ Groups }} & \multirow{4}{*}{$\begin{array}{l}\text { DPPH scavenging \% } \\
\text { (Mean } \pm \text { SD) } \\
64.79 \pm 4.87\end{array}$} & \multirow{4}{*}{$\begin{array}{l}\text { S.E } \\
0.77\end{array}$} & \multicolumn{2}{|c|}{ Confidence Interval 95\% } & \multirow{3}{*}{$\begin{array}{l}\text { P-Value } \\
.000\end{array}$} \\
\hline & & & & \multirow{2}{*}{$\begin{array}{l}\text { Lower } \\
15.6187\end{array}$} & \multirow{2}{*}{$\begin{array}{l}\text { Upper } \\
19.5068\end{array}$} & \\
\hline & \multirow{6}{*}{ Serum } & & & & & \\
\hline & & & & 19.3968 & 24.1588 & .000 \\
\hline \multirow{2}{*}{ G2 } & & \multirow{2}{*}{$47.22 \pm 4.50$} & \multirow{2}{*}{0.71} & -19.5068 & -15.6187 & .000 \\
\hline & & & & 1.8341 & 6.5960 & .001 \\
\hline \multirow{2}{*}{ G3 } & & \multirow{2}{*}{$43.01 \pm 2.74$} & \multirow{2}{*}{0.61} & -24.1588 & -19.3968 & .000 \\
\hline & & & & -6.5960 & -1.8341 & .001 \\
\hline \multirow{2}{*}{ G1 } & \multirow{6}{*}{ Mucus } & \multirow{2}{*}{$21.24 \pm 3.62$} & \multirow{2}{*}{0.57} & 4.5929 & 6.8647 & .000 \\
\hline & & & & 10.1120 & 12.8945 & .000 \\
\hline \multirow{2}{*}{ G2 } & & \multirow{2}{*}{$15.51 \pm 1.41$} & \multirow{2}{*}{0.22} & -6.8647 & -4.5929 & .000 \\
\hline & & & & 4.3833 & 7.1657 & .000 \\
\hline \multirow{2}{*}{ G3 } & & \multirow{2}{*}{$9.73 \pm 1.53$} & \multirow{2}{*}{0.34} & -12.8945 & -10.1120 & .000 \\
\hline & & & & -7.1657 & -4.3833 & .000 \\
\hline
\end{tabular}

The investigations of this results may be due to the chronic infection in cervix cause increased the number of leukocytes in the location (mucus) of inflammation and this lead to elevated levels of reactive oxygen species (ROS) such as superoxide and hydrogen peroxide to destroy the microorganisms that cause this inflammation such as HPV, bacteria or fungi. Also depletion of antioxidants in the immunity defense process.

Moreover, there are found significant lowering in G3 compared to G2, because of the viral cause desquamation for the epithelial tissues in chronic cervical infection and maybe cause epithelial cells necrosis, then increase electron leakage from the mitochondria and depleted the antioxidants. Therefore, the lowering antioxidants in the body (serum) or cells lead to reduce the ability to scavenging DPPH compared with healthy persons.

\section{Conclusion}

In brief, DPPH scavenging activity from the primary methods to estimation the antioxidants status of the body. In the patients show the lowering in the antioxidants due to inflammation compared with healthy women. The deterioration in the antioxidants levels can cause cancer in the future or delay the response of the medication to inflammation.

Ethical Clearance: The Research Ethical Committee at scientific research by ethical approval of both environmental and health and higher education and scientific research ministries in Iraq

Conflict of Interest: The authors declare that they have no conflict of interest.

Funding: Self-funding

\section{References}

1. Mattson SK, Polk JP, Nyirjesy P. Chronic cervicitis: presenting features and response to therapy. J Low Genit Tract Dis. 2016;20(3):e30-3.

2. Su Y, Zhang M, Zhang W, Shi H. Clinical efficacy of cryotherapy combined with interferon in the 
treatment of chronic cervicitis complicated with HPV infection. Pak J Pharm Sci. 2017;30.

3. Chen X, Guo H. Comparison of ChlorquinaldolPromestriene Vaginal Tablets and Opin Suppositories Effect on Inflammatory Factors and Immune Function in Chronic HPV Cervicitis. J Coll Physicians Surg Pakistan. 2019;29(2):115-8.

4. Kumar A, Kumar A. Chronic Cervicitis. J Minim Invasive Gynecol [Internet]. 2018;25(1):45. Available from: https://doi.org/10.1016/j. jmig.2017.02.015

5. Vermund SH, Kelley KF. Impact of HIV on human papilloma virus-mediated cervical disease progression. Aids. 2018;32(12):1715-7.

6. Han L, Maimaitiming T, Husaiyin S, Wang L, Wusainahong K, Ma C, et al. Comparative study of HPV16 integration in cervical lesions between ethnicities with high and low rates of infection with high-risk HPV and the correlation between integration rate and cervical neoplasia. Exp Ther Med. 2015;10(6):2169-74.

7. Singh S, Singh RP. In vitro methods of assay of antioxidants: an overview. Food Rev Int. 2008;24(4):392-415.

8. CuiK, Luo X, Xu K, Murthy MRV. Role of oxidative stress in neurodegeneration: recent developments in assay methods for oxidative stress and nutraceutical antioxidants. Prog Neuro-Psychopharmacology Biol Psychiatry. 2004;28(5):771-99.

9. Halliwell B. Commentary oxidative stress, nutrition and health. Experimental strategies for optimization of nutritional antioxidant intake in humans. Free Radic Res. 1996;25(1):57-74.

10. Molyneux P. The use of the stable free radical diphenylpicryl- hydrazyl (DPPH) for estimating antioxidant activity. J Sci Technol. 2004;26(2):2119.

11. Okunowo AA, Daramola ES, Soibi-Harry AP, Ezenwankwo FC, Kuku JO, Okunade KS, et al. Women's knowledge of cervical cancer and uptake of Pap smear testing and the factors influencing it in a Nigerian tertiary hospital. J Cancer Res Pract [Internet]. 2018;5(3):105-11. Available from: https://linkinghub.elsevier.com/retrieve/pii/ S2311300617301490

12. Gravitt PE, Peyton CL, Alessi TQ, Wheeler $\mathrm{CM}$, Coutlee F, Hildesheim A, et al. Improved amplification of genital human papillomaviruses. J Clin Microbiol. 2000;38(1):357-61.

13. Juckett G. H-AHAF. Effects of topical PaiTeLing in nude mice implanted with human condyloma acuminatum tissue infected with HPV 6, 31, and 81: comparison with imiquimod and interferon- $\alpha-$ 2b. bioRxiv. 2010;536-63.

14. Pavithra K, Vadivukkarasi S. Evaluation of free radical scavenging activity of various extracts of leaves from Kedrostis foetidissima (Jacq.) Cogn. Food Sci Hum Wellness [Internet]. 2015;4(1):426. Available from: https://linkinghub.elsevier.com/ retrieve/pii/S2213453015000130 